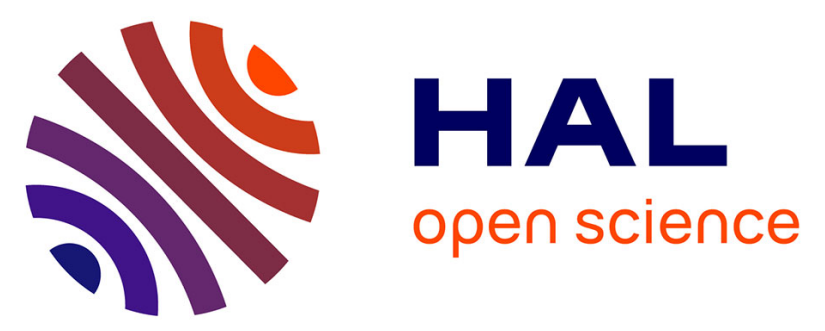

\title{
Effects of hydrogen and steam addition on laminar burning velocity of methane-air premixed flame: Experimental and numerical analysis
}

Toufik Boushaki, Yannick Dhué, Laurent Selle, Bernard Ferret, Thierry Poinsot

\section{To cite this version:}

Toufik Boushaki, Yannick Dhué, Laurent Selle, Bernard Ferret, Thierry Poinsot. Effects of hydrogen and steam addition on laminar burning velocity of methane-air premixed flame: Experimental and numerical analysis. International Journal of Hydrogen Energy, 2012, vol. 37, pp.9412-9422. 10.1016/j.ijhydene.2012.03.037 . hal-00800989

\section{HAL Id: hal-00800989 \\ https://hal.science/hal-00800989}

Submitted on 14 Mar 2013

HAL is a multi-disciplinary open access archive for the deposit and dissemination of scientific research documents, whether they are published or not. The documents may come from teaching and research institutions in France or abroad, or from public or private research centers.
L'archive ouverte pluridisciplinaire HAL, est destinée au dépôt et à la diffusion de documents scientifiques de niveau recherche, publiés ou non, émanant des établissements d'enseignement et de recherche français ou étrangers, des laboratoires publics ou privés. 


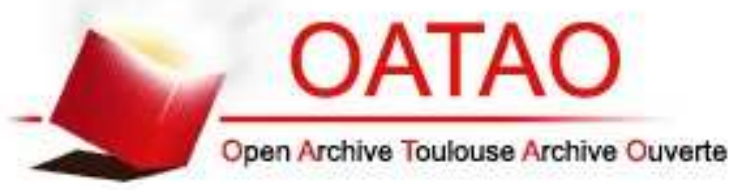

\section{Open Archive TOULOUSE Archive Ouverte (OATAO)}

OATAO is an open access repository that collects the work of Toulouse researchers and makes it freely available over the web where possible.

This is an author-deposited version published in : http://oatao.univ-toulouse.fr/ Eprints ID : 8576

To link to this article : DOI: 10.1016/j.ijhydene.2012.03.037

URL : http://dx.doi.org/10.1016/j.ijhydene.2012.03.037

To cite this version :

Boushaki, Toufik and Dhué, Yannick and Selle, Laurent and Ferret, Bernard and Poinsot, Thierry Effects of hydrogen and steam addition on laminar burning velocity of methane-air premixed flame: Experimental and numerical analysis. (2012) International Journal of Hydrogen Energy, vol. 37 ( $\left.{ }^{\circ} 11\right)$. pp. 9412-9422. ISSN 0360-3199

Any correspondence concerning this service should be sent to the repository administrator: staff-oatao@ listes.diff.inp-toulouse.fr 


\title{
Effects of hydrogen and steam addition on laminar burning velocity of methane-air premixed flame: Experimental and numerical analysis
}

\author{
T. Boushaki ${ }^{a, b, *}$, Y. Dhuéc, L. Selle ${ }^{c}$, B. Ferret ${ }^{c}$, T. Poinsot ${ }^{c}$ \\ a ICARE CNRS, 1C, Avenue de la Recherche Scientifique, 45071 Orléans Cedex 2, France \\ ${ }^{\mathrm{b}}$ University of Orléans, IUT, GTE - 45067 Orléans cedex 2, France \\ ${ }^{\mathrm{C}}$ Université de Toulouse, INPT, UPS, IMFT, Allée Camille Soula, F-31400 Toulouse, France
}

Keywords:

Laminar flame

Burning velocity

Hydrogen addition

Steam addition

Slot burner

\begin{abstract}
A B S T R A C T
Effects of hydrogen enrichment and steam addition on laminar burning velocity of methane-air premixed flame were studied both experimentally and numerically. Measurements were carried out using the slot burner method at 1 bar for fresh gases temperatures of $27{ }^{\circ} \mathrm{C}$ and $57{ }^{\circ} \mathrm{C}$ and for variable equivalence ratios going from 0.8 to 1.2. The hydrogen content in the fuel was varied from $0 \%$ to $30 \%$ in volume and the steam content in the air was varied from 0 to $112 \mathrm{~g} / \mathrm{kg}(0-100 \%$ of relative humidity). Numerical calculations were performed using the COSILAB code with the GRI-Mech 3.0 mechanism for one-dimensional premixed flames. The calculations were implemented first at room temperature and pressure and then extended to higher temperatures (up to $917 \mathrm{~K}$ ) and pressures (up to 50 bar). Measurements of laminar burning velocities of methanehydrogen-air and methane-air-steam agree with the GRI-Mech calculations and previous measurements from literature obtained by different methods. Results show that enrichment by hydrogen increases of the laminar burning velocity and the adiabatic flame temperature. The addition of steam to a methane-air mixture noticeably decreases the burning velocity and the adiabatic flame temperature. Modeling shows that isentropic compression of fresh gases leads to the increase of laminar burning velocity.
\end{abstract}

\section{Introduction}

Natural gas offers an interesting alternative to traditional fuels to reduce pollutant emissions and to lower the energy dependence of road vehicles on oil. The addition of hydrogen to natural gas has even more advantages in terms of pollutant reduction, thermal efficiency, and combustion stability allowing some combustion systems to operate with lean fuel mixtures. Hydrogen offers high flame speeds, a wide flammability range [1-3], low minimum ignition energy and no emissions of $\mathrm{HC}$ or $\mathrm{CO}_{2}[4,5]$. It is actually considered as one of the most promising alternative fuels for future engines. Combination of hydrogen with other fuels is one effective approach to use of hydrogen for clean combustion. Recent studies on internal combustion engines with hydrogenenriched fuels showed that hydrogen addition could increase thermal efficiency, improve lean burn capability and mitigate the global warming problem [4,6-8]. Due to lower

\footnotetext{
* Corresponding author. ICARE CNRS, 1C, Avenue de la Recherche Scientifique, 45071 Orléans Cedex 2, France. Tel.: +33 (0) 238255070 ; fax: +33 (0) 238257875 .

E-mail address: toufik.boushaki@cnrs-orleans.fr (T. Boushaki).
} 
temperatures of very lean flames, NOx emissions also decreased significantly [9].

In many combustion systems, a factor which is often neglected to predict combustion characteristics is the presence of water in the combustion air. This water may come from the ambient atmosphere feeding the combustor. It may also be introduced on purpose using for example EGR in internal combustion engines, or liquid water injection in gas turbines to reduce the NOx emissions [10-12]. The presence of steam modifies the combustion process in a more or less significant way. However, few studies on steam addition effects on combustion characteristics were conducted. The present work, therefore, aims at studying the combined effects of hydrogen enrichment and water injection on methane/air combustion and particularly on the laminar burning velocity. Lif and Holmberg [13] studied the injection effect of water-in-diesel emulsions on the emissions and on the combustion efficiency in diesel engine. For an emulsion containing $15 \%$ of water, the authors showed a decrease of $30 \%$ in NOx and $60 \%$ in particle emissions; however, the $\mathrm{CO}$ and HC emissions increased. Other types of fuel have also been studied such as LPG [14] and recently pure hydrogen [15].

The enrichment by hydrogen or the addition of steam modifies the laminar burning velocity. The laminar burning velocity is an important parameter for validating chemical kinetics, for the modeling of turbulent combustion and for the design of practical devices. Flame velocities of methane-air [16-20] and hydrogen-air [21-25] mixtures have already been extensively studied. Some studies have been independently performed on methane-hydrogen-air [26,27,33,34] and methane-steam-air mixtures [28,29,40,41]. However, very limited studies have been conducted on the combined effects of pressure and temperature on the combustion of these mixtures. Milton and Keck [30] reported laminar flame velocities of hydrocarbon-hydrogen-air mixtures, as functions of the mixture temperature and pressure, by using a spherical combustion bomb. Because of the multitude of parameters of the investigation, the study was limited to stoichiometric concentrations. Yu et al. [26] extended the study to the complete ranges of equivalence ratio under normal temperature and pressure. Halter et al. [31] investigated the pressure effect on laminar burning velocity for $\mathrm{CH}_{4}-\mathrm{H}_{2}$ flames and the results showed an increase in $\mathrm{S}_{\mathrm{L}}$ with $\mathrm{H}_{2}$ addition and a decrease in $S_{L}$ with the increase of initial pressure. Hu et al. [32] studied the laminar burning velocities and onset of cellular instabilities of methane-hydrogen-air mixtures using a constant volume combustion chamber for equivalence ratio of 0.8 , at different initial pressures, initial temperatures, and hydrogen fractions. The authors found that the unstretched flame propagation speed and the unstretched laminar burning velocity increase with the increase of initial temperature and hydrogen fraction, and they decrease with the increase of initial pressure. Wang et al. [33] recently reported the chemical kinetics effect of hydrogen addition on the characteristics of methane-air mixtures combustion by using Premix in the Chemkin II program with the GRI-Mech 3.0 mechanism. They showed that the promotion of chemical reaction with hydrogen addition is due to the increase of $\mathrm{H}, \mathrm{O}$ and $\mathrm{OH}$ mole fractions in the flame as hydrogen is added.
Tahtouh et al. [34] studied in the effects of hydrogen addition and nitrogen dilution on the laminar flame characteristics of premixed methane-air flames. Measurements were performed at initial conditions of $0.1 \mathrm{MPa}$ and $300 \mathrm{~K}$ and stoichiometricmixture using spherically expanding flames in a constant volume vessel.

The effect of steam addition on the burning velocity is reported by some authors in the case of hydrogen-air flames [22,35-39], whereas in the case of methane-air mixtures the studies are very limited. The measurements of Fells and Rutherford [28] and calculations of Le Cong and Dagaut [29] on the $\mathrm{CH}_{4}$-air and natural gas-air flames, respectively, showed that the addition of water vapor yields lower flame velocity, lower adiabatic temperature, and reduced NOx formation. Kinetic analyses indicated that the reduction of NO emission by $\mathrm{H}_{2} \mathrm{O}$ injection is mostly due to dilution, reduction of $\mathrm{N}_{2}$ concentration, and thermal effects. Babkin and V'yun [40] investigated effects of water vapor on the $\mathrm{CH}_{4}$-air flame velocity at high pressures by a spherical bomb apparatus for a stoichiometricmixture. They noted the linear decrease of laminar burning velocity with steam addition at both atmospheric and elevated pressures. Recently, Mazas et al. [41] investigated the effects of water vapor on the laminar burning velocity of a methane oxygen-enriched flame at atmospheric pressure and for an unburned gas temperature $\mathrm{T}_{u}=373 \mathrm{~K}$. Flame velocities were measured by the Schlieren method based on the flame area in a burner with a conical flame. They showed that flame speeds decrease when the steam concentration is increased. Their results indicated that steam addition has a significant chemical effect on laminar burning velocities, in particular in lean and nearstoichiometric conditions. However this impact is reduced when the oxygen concentration is increased in the reactive mixture. For highly oxygen-enriched flames, steam can be considered as an inert diluent, even at high steam concentrations.

The measurement of laminar burning velocity has always been a complicated issue leading to multiple methods. As early as 1939, Laffitte [42] cited many methods to measure the flame velocity. The various experimental configurations used for flame velocities may be classified as follows: (a) conical stationary flames on cylindrical tubes and nozzles; (b) flames in tubes; (c) soap bubble method; (d) constant volume explosion in spherical vessel; (e) flat flame methods. The methods are listed in order of decreasing complexity of flame surface and correspond to an increasing complexity of experimental arrangement. Each has certain advantages that attend its usage [43-45].

In the present work, the slot burner method is used to measure the laminar burning velocity and COSILAB code [46] using GRI-Mech 3.0 [47] for the calculations in order to characterize the effects of hydrogen and steam addition on the methane-air combustion over a wide range of operating conditions. The measurement of flame speed by the slot burner method is based on the measurement of the flame surface. Many factors can influence the measurement: heat loss, air entering the flame base, curvature, strain. Indeed, in a previous study [48] the authors analyzed the effects of these factors and showed that the burner method allows to measure flame velocities with a good accuracy, comparable to other 
measurement methods. The advantage of this method is its simplicity of use since the flame is stationary and can be easily characterized by its surface or angle.

\section{Experimental method}

The scheme of the slot burner is shown in Fig. 1a. It consists of the burner head which is a nozzle of $150 \mathrm{~mm}$ high mounted on a plenum chamber of $370 \mathrm{~mm}$ high. The system is designed to have a homogeneous and laminar mixture at the nozzle exit. The plenum is constituted of three parts: a mixer of cylindrical form (70 mm high, $\varnothing=200 \mathrm{~mm}$ ), then a square section containing a pileup of glass balls $\left(\varnothing_{\text {ball }}=10 \mathrm{~mm}\right.$ ) with $100 \mathrm{~mm}$ height and various honeycombs $(15 \mathrm{~mm}$ high and $5 \mathrm{~mm}$ cellsize), and finally a converging unit (100 $\mathrm{mm}$ high) sized up to have a velocity profile as flat as possible at the exit. The slot used to stabilize the flame is $l=10 \mathrm{~mm}$ wide and $L=100 \mathrm{~mm}$ long. The nozzle is cooled by a regulated water circuit placed on both sides of the nozzle to avoid high thermal gradients within the flow. In the mixer, the air is injected tangentially in order to create a swirling flow promoting mixing with fuel jets. Flow rates are controlled and measured using Bronkhorst flow meters (F-201AV-AAA-33-V for air, F-201CV-AAA-33-V for $\mathrm{CH}_{4}-\mathrm{H}_{2}$, L23-AAD-33-O for steam). The temperature of fresh gases is controlled by heating air with a Bronkhorst heated evaporator-mixer (Controlled Evaporator Mixer, CEM W-303330-K). The CEM is also used to generate air containing steam.

Flame velocities are measured at atmospheric pressure and temperature of $27^{\circ} \mathrm{C}$ and $57^{\circ} \mathrm{C}$ of fresh gases and for variable equivalence ratios ( $\phi: 0.8-1.2)$. The mean bulk velocity at the exit nozzle is fixed at $U=1.9 \mathrm{~m} / \mathrm{s}$. The hydrogen mole fraction in the fuel

$$
\alpha=\frac{\mathrm{H}_{2}}{\mathrm{CH}_{4}+\mathrm{H}_{2}}
$$

is varied between 0 and 0.3 . The content of steam in air is expressed by the specific humidity

$\mathrm{S}_{\mathrm{H}}=\frac{m_{\mathrm{H}_{2} \mathrm{O}}}{m_{\mathrm{air}}+m_{\mathrm{H}_{2} \mathrm{O}}}$

which is varied from 0 to $21.8 \mathrm{~g} / \mathrm{kg}(0-100 \%$ of relative humidity) for $T_{u}=300 \mathrm{~K}$ and from 0 to $112.1 \mathrm{~g} / \mathrm{kg}(0-100 \%$ of relative humidity) for $T_{u}=330 \mathrm{~K}$. It is worth noting that the maximum value of steam content contained in the air is increased significantly by the increase of the initial gas temperature.

The principle of flame velocity measurements on a slot burner type is based on the mass conservation between the outlet nozzle and the flame front. The average flame velocity along the flame surface in the transverse plane can be expressed by:

$\bar{S}_{\mathrm{L}}=\frac{U l}{\mathrm{~L}_{f}}$

where $U$ is the mean bulk velocity, $l$ is the width of the slot and $L_{f}$ is the length of the flame front at the center of the burner. Eq. (3) expresses from mass conservation between the burner exit and the flame front, considering that the flame speed $S_{L}$ is constant over the flame surface. The unstretched laminar burning velocity $S_{L}$ can be obtained from $\bar{S}_{L}$ and a factor of correction due to three-dimensional effect, curvature, strain

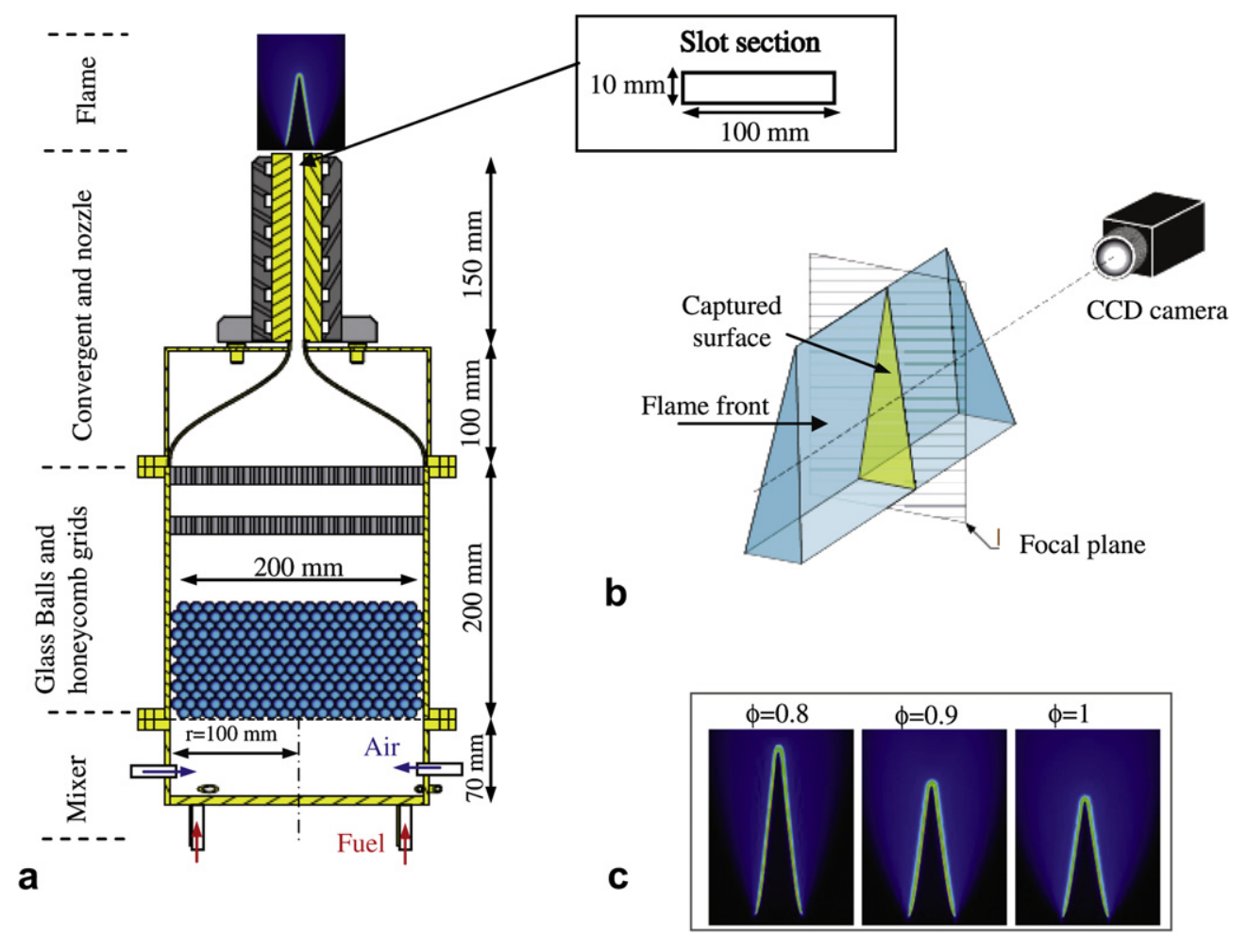

Fig. 1 - a) Schematic of the slot burner, b) Schematic of flame front from the slot burner, c) Example of $\mathrm{CH}_{4}-$ air flame images for equivalence ratios $0.8,0.9$ and 1 . 
and heat losses to the walls: $S_{L}=\bar{S}_{L} \eta$. The correction factor is equal to 1.059 in this work [48] and is kept constant for all experiments. It was determined using numerical simulations on the same geometry of the burner. The results showed a small error $(=0.5 \%)$ due to curvature, strain and heat losses to the solid. The main error is due to the 3D effects (at the extremities of the slot) and is about $5.4 \%$ according to the velocity measurements carried out at the nozzle exit on the one hand, and the analytical calculation based on the study of Tatsumi and Yoshimura [49] on the other hand. This error is due to the flow acceleration (5.4\% increase compared to the mean velocity over the entire nozzle) at the center of the nozzle where the flame surface is measured.

The flame front area which allows to determinate the flame velocity $\left(\bar{S}_{L}\right)$ is determined by flame imaging. The flame images are captured by a Guppy CCD camera of $1392 \times 1024$ pixel array with a 200-mm Nikon Micro Nikkor lens (f/4.0 D). The camera system is of high sensitivity, large dynamic range and large well capacity. Therefore, the flame images can be captured clearly by the camera. An example of $\mathrm{CH}_{4}$-air flame images for the equivalence ratios $0.8,0.9$ and 1 is illustrated in Fig. 1c. For each experimental condition, 30 images of the flame were captured to possibly eliminate the effect of small fluctuations to the flame velocity. The images are processed in Matlab software to locate the flame front and to measure the flame area. The flame from the slot burner has a prismatic form as shown in Fig. 1.b. The flame surface is determined at the center of burner based on these visualizations.

\section{Computational method}

Numerical simulations of laminar, one-dimensional, premixed, and freely propagating flames are carried out with COSILAB code using the GRI-Mech 3.0 mechanism for $\mathrm{CH}_{4}-$ air $-\mathrm{H}_{2}$ and $\mathrm{CH}_{4}-$ air $-\mathrm{H}_{2} \mathrm{O}$ mixtures. GRI 3.0 consists of 325 elementary chemical reactions with associated rate coefficient expressions and thermochemical parameters for the 53 species. It includes a detailed combustion reaction mechanism for hydrogen. The GRI 3.0 mechanism has been validated by large experimental data for methane, ethane, carbon monoxide and hydrogen. In the case of methane-hydrogen flames, GRI-Mech has been used by some authors $[1,31,50,51]$ and proven to have high accuracy. Measurements and calculations of flame velocity for a $\mathrm{CH}_{4}$-air mixture with steam addition are very limited. However, for a flame $\mathrm{CH}_{4}-\mathrm{O}_{2}-$ air $-\mathrm{H}_{2} \mathrm{O}$, Mazas et al. [41] found a good agreement between measured and computed laminar flame velocity using GRI-Mech 3.0 mechanism. In the present work, the GRIMech 3.0 is tested for different parameters such as initial temperature, equivalence ratio and fraction of water vapor for a $\mathrm{CH}_{4}$-air flame.

In the computations, the windward differencing on both convective and diffusion terms are used. The gradient and curvature values are 0.01 and 0.2 , respectively, to control the adaptive grid. The calculation domain is from $0 \mathrm{~mm}$ upstream to $20 \mathrm{~mm}$ downstream; total number of grid points is typically 350-400.

The calculations are implemented first at atmospheric pressure and room temperature $(300 \mathrm{~K}, 1$ bar) then at elevated initial pressures and temperatures. The mole fraction of hydrogen in the $\mathrm{CH}_{4}+\mathrm{H}_{2}$ mixture is varied from 0 to 0.5 and the equivalence ratio is varied from 0.6 to 1.4.

\section{Results and discussion}

\subsection{Laminar burning velocity of methane/air flame}

Fig. 2 shows the calculated and measured laminar burning velocity as a function of equivalence ratio for methane-air mixtures at $300 \mathrm{~K}$ and 1 bar. The present results are compared with literature data $[9,16-20,31]$ where measurements were carried out using different measurement methods. The experimental data obtained for the slot burner are compared to the numerical calculations performed with COSILAB code using the GRI-Mech 3.0 reaction mechanism. Measurements are in very good agreement with the modeling for all equivalence ratios $(\phi=0.8-1.2)$. The measurement data of the literature are a little scattered corresponding to the different methods used by the authors and to measurement errors. However, $S_{L}$ results globally follow a similar behavior as a function of the equivalence ratio. In our data, the laminar burning velocity peaks for an equivalence ratio of 1.05 and falls off for both the rich and lean mixtures. Compared to the different results from the literature, this peak of $S_{L}$ is either at $\phi=1.05[9,18,19]$ or at $\phi=1.1[16,17,20,31]$. For a stoichiometric mixture, the value of laminar burning velocity found by different authors ranges from 33 to $43 \mathrm{~cm} / \mathrm{s}$. However, the recent experiments converge toward a value around $S_{L}=(36 \pm 1) \mathrm{cm} / \mathrm{s}$. The value of $S_{L}$ obtained from our slot burner $(37.2 \mathrm{~cm} / \mathrm{s})$ is very close to the results of Edmondson and Heap [21] $(37.0 \mathrm{~cm} / \mathrm{s}$, by the burner method), Van Maaren et al. [16] $(37.0 \mathrm{~cm} / \mathrm{s}$, by the flat flame-heat flux method), Clarke et al. [52] $(36.8 \mathrm{~cm} / \mathrm{s}$, by the closed vessel method), Vagelopoulos and Egolfopoulos [17] $(36.7 \mathrm{~cm} / \mathrm{s}$, by couterflow

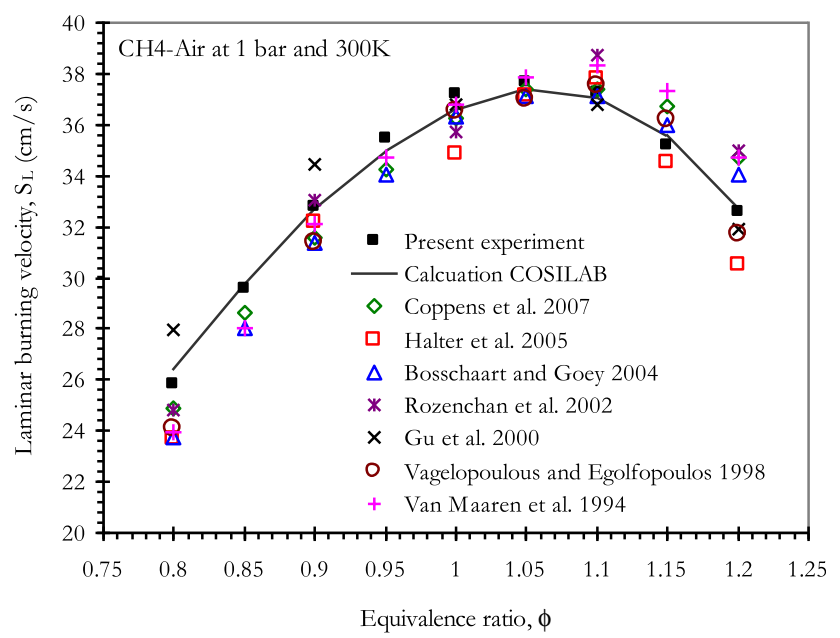

Fig. 2 - Calculated and measured laminar burning velocity of methane/air mixtures, and comparison with experimental data from literature using different configurations. Symbols represent experimental data; line represents calculation with COSILAB (using GRI3.0 mechanism). 
method) and $\mathrm{Gu}$ et al. [18] $(36.8 \mathrm{~cm} / \mathrm{s}$, by the closed vessel method). This comparison shows that the present values of flame velocities are consistent with the data from the literature. Over the measured range of equivalence ratio, it appears that the results are slightly higher than other experiments for lean flames, except for the data of Gu et al. [18], and slightly below them for rich flames, except for the data of Halter et al. [31]. Considering the error bars on all flame velocity measurements (see for example a summary of measured values by different methods for methane-air flames in [19]), it is difficult to determine which method is the best, however the present one obviously gives reasonable results and matches GRI-Mech 3 mechanism results very well.

\subsection{Effect of hydrogen addition}

The effects of hydrogen addition on the laminar burning velocity at temperature $300 \mathrm{~K}$ and atmospheric pressure are shown in Fig. 3. Hydrogen content in the fuel is varied from $0 \%$ to $30 \%$ in volume. In the case of $30 \%$ hydrogen, the measurements only concern lean mixtures, because the flame flashes back for the stoichiometricand rich conditions. To prevent this flashback, it is necessary either to increase the injection velocity thus the flow rate, or to decrease the area of the exit burner. In Fig. 3 symbols represent measurements and lines represent numerical calculations by GRI-Mech. For a given equivalence ratio, when the hydrogen fraction in the fuel increases, the laminar burning velocity increases, as expected. This is due to the high mass and thermal diffusivity of hydrogen in air and its high reactivity. Between 0 and $25 \%$ of $\mathrm{H}_{2}$ at stoichiometry, $\mathrm{S}_{\mathrm{L}}$ increases from 37 to $46 \mathrm{~cm} / \mathrm{s}$, an increase of about $25 \%$. This increase of laminar burning velocity would lead to very different performances in real combustion systems. For the different hydrogen fractions, the variation of laminar burning velocity with equivalence ratio is qualitatively the same. The maxima of $S_{L}$ are found in

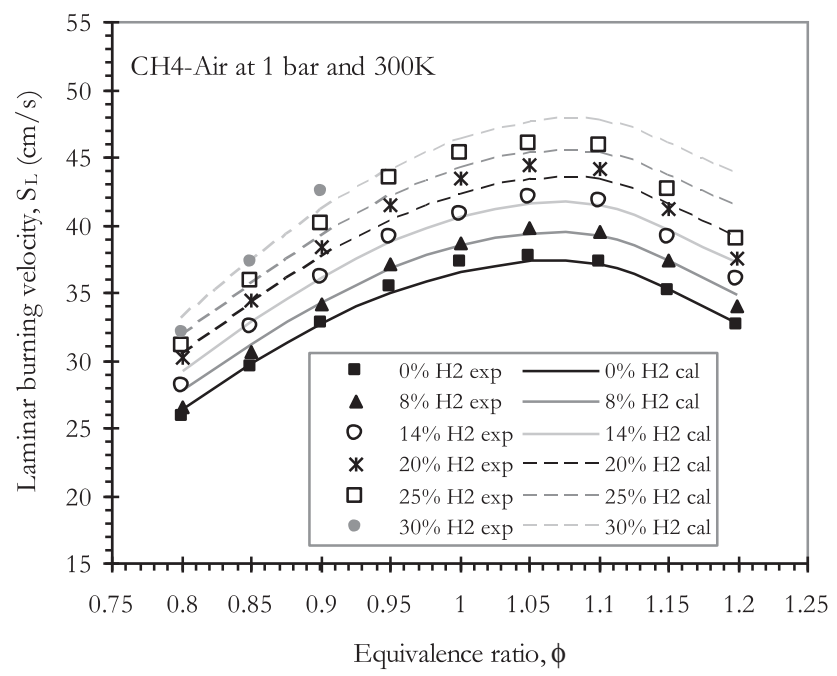

Fig. 3 - Laminar burning velocity as a function of equivalence ratio for methane-hydrogen-air mixtures $(\alpha: 0-30 \%)$ at 1 bar pressure and $300 \mathrm{~K}$. Symbols represent experimental data; lines represent calculations with COSILAB (GRI3.0 mechanism). a narrow range of $\phi$, from 1 to 1.1 in the studied range of hydrogen fraction. The comparison between measurements and calculations indicates a good agreement for an equivalence ration range of $0.8-1.1$. In very rich mixtures $\phi=1.2$, the values of $S_{L}$ are more scattered, maybe because the flame starts to lose its triangular shape. Many studies showed that the maximum value of $S_{L}$ shifts to the rich mixture region with increasing hydrogen fraction in fuel blends [2,33,50,53]. Ilbas et al. [2] obtained a maximum burning velocity $\mathrm{S}_{\mathrm{Lmax}}=3.2 \mathrm{~m} / \mathrm{s}$ and was obtained at the equivalence ratio $\phi=1.8$. Tang et al. [53] found two regimes, $0-80 \% \mathrm{H}_{2}$ and $80-100 \% \mathrm{H}_{2}$, of $\mathrm{S}_{\mathrm{L}}$ increment with $\mathrm{H}_{2}$ fraction. They found that the increment of $S_{L}$ from 80 to $100 \%$ is three or four times that from 0 to $80 \%$.

Fig. 4 shows measured laminar burning velocity as a function of equivalence ratio compared with those of the literature $[9,31]$ for different hydrogen content in the fuel. The measurements of Coppens et al. [9] were performed using the heat flux method (flat flame) while the investigation of Halter et al. [31] was performed using the spherical bomb method. Globally the variation of $S_{L}$ with equivalence ratio is practically identical for all authors. Our results of slot burner are very close to those obtained by Coppens et al. [9] for $\mathrm{H}_{2}$ mole fractions 0, 15 and 25\%. However there is a slight difference between the two methods and with the results of Halter et al. [31] due to measurement errors and the experimental methods used.

In order to investigate the effect of hydrogen addition on the flame speed more clearly, the measured laminar burning velocity with hydrogen content is illustrated in Fig. 5 , for the equivalence ratios $0.8,1$ and 1.2 compared to the data from the literature. The study of Uykur et al. [27] is a numerical simulation performed by CHEMKIN III with GRI 3.0 as kinetic mechanism. Ilbas et al. [2] determined the flame speed within the bomb using a high-speed Schlieren photographic technique. The measurements of Shy and al. [55] were based on flame propagation in a cylinder from a cruciform burner. The results show that the laminar burning velocity increases linearly with increasing hydrogen content over the range of investigation $\left(0-25 \%\right.$ of $\left.\mathrm{H}_{2}\right)$. The present work gives data consistent with results from the literature. The linearity of $S_{L}$ with hydrogen fraction is found for all the equivalence ratios and all experimental method, except for the study of Shy et al. [55] for the case of $\phi=0.8$. The same behavior was observed later by the authors Yu et al. [26], Halter et al. [31] and Di Sarli and Di Benedetto [50]. For higher hydrogen contents (>50\%) Di Sarli and Benedetto [50] showed that the increase of $S_{L}$ is significant and becomes non-linear. From 0 to $100 \% \mathrm{H}_{2}$, Huang et al. [54] found that the increments of the unstretched laminar burning velocity increase exponentially with the increase of hydrogen fraction in fuel blends.

The adiabatic flame temperature is an important parameter of combustion because it determines the amount of heat from the flame and also acts on mechanisms of pollutant formation. Any modification of this temperature therefore leads to changes in other variables. Furthermore, since the reaction rate coefficient in Arrhenius equation has high temperature dependence, the temperature must have great effect on the chemical reaction process. Calculated adiabatic flame temperatures $\left(T_{\mathrm{ad}}\right)$ are displayed in Fig. 6.a versus 

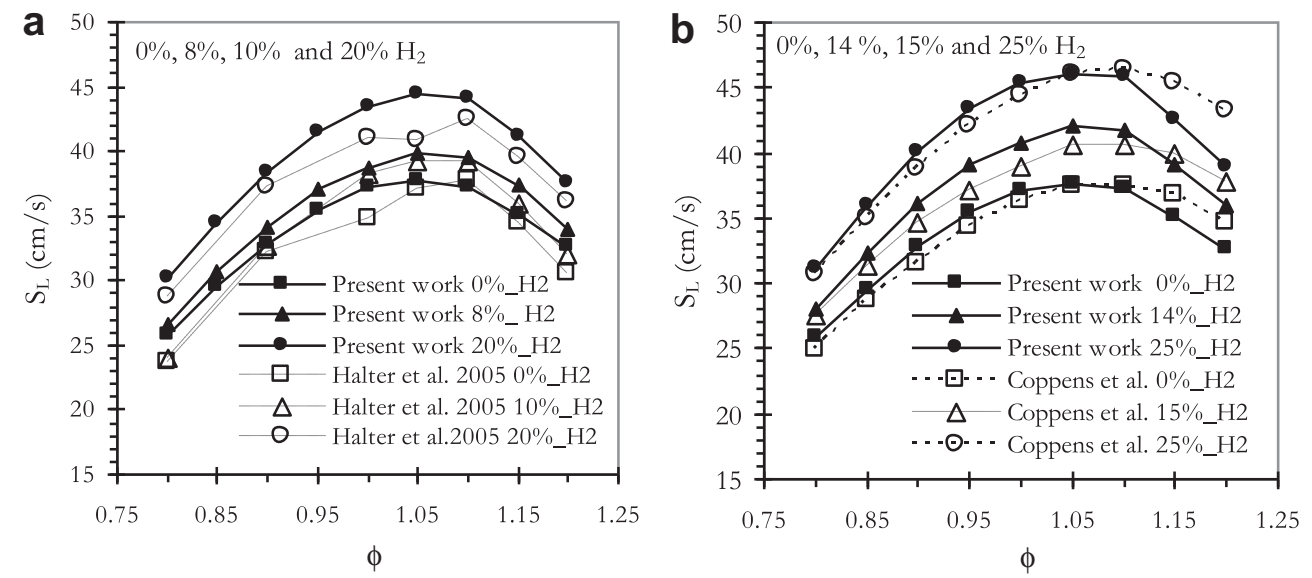

Fig. 4 - Laminar burning velocity versus the equivalence ratio for various percentage of hydrogen; a) comparison with the data experimental of Coppens et al. [9] (Heat flow method), b) comparison with the data experimental of Halter et al. [31] (Closed vessel method).

equivalence ratio for hydrogen fractions 0,20 and 50 percent. Fig. $6 \mathrm{~b}$ shows $\mathrm{T}_{\mathrm{ad}}$ variations with hydrogen fraction at the stoichiometry. The flame temperature reaches its maximum value around the stoichiometry. The addition of hydrogen induces a slight increase in adiabatic flame temperature. For the equivalence ratio of 1 , adding $20 \%$ of $\mathrm{H}_{2}, \mathrm{~T}_{\text {ad }}$ increases from 2223 to $2233 \mathrm{~K}$ (i.e. $10 \mathrm{~K}$ more), and adding $50 \%$ of $\mathrm{H}_{2}, \mathrm{~T}_{\mathrm{ad}}$ increases to $2256 \mathrm{~K}$, i.e. $33 \mathrm{~K}$ more than in the combustion of pure methane. The results show that for the present range of hydrogen addition ( $0-30 \%$ of $\mathrm{H}_{2} \%$ ), the flame temperature varies only slightly as found also by Wang et al. [33]. Indeed, they observed that $\mathrm{T}_{\text {ad }}$ increases by $10 \mathrm{~K}$ from 0 to $20 \% \mathrm{H}_{2}$ and $10 \mathrm{~K}$ more from 20 to $40 \% \mathrm{H}_{2}$ addition in the methane-hydrogen fuel blends. Uykur et al. [27] calculations showed that the fame temperature of the mixture was increased by less than $1 \%$ with the addition of $20 \% \mathrm{H}_{2}$. The increase of flame
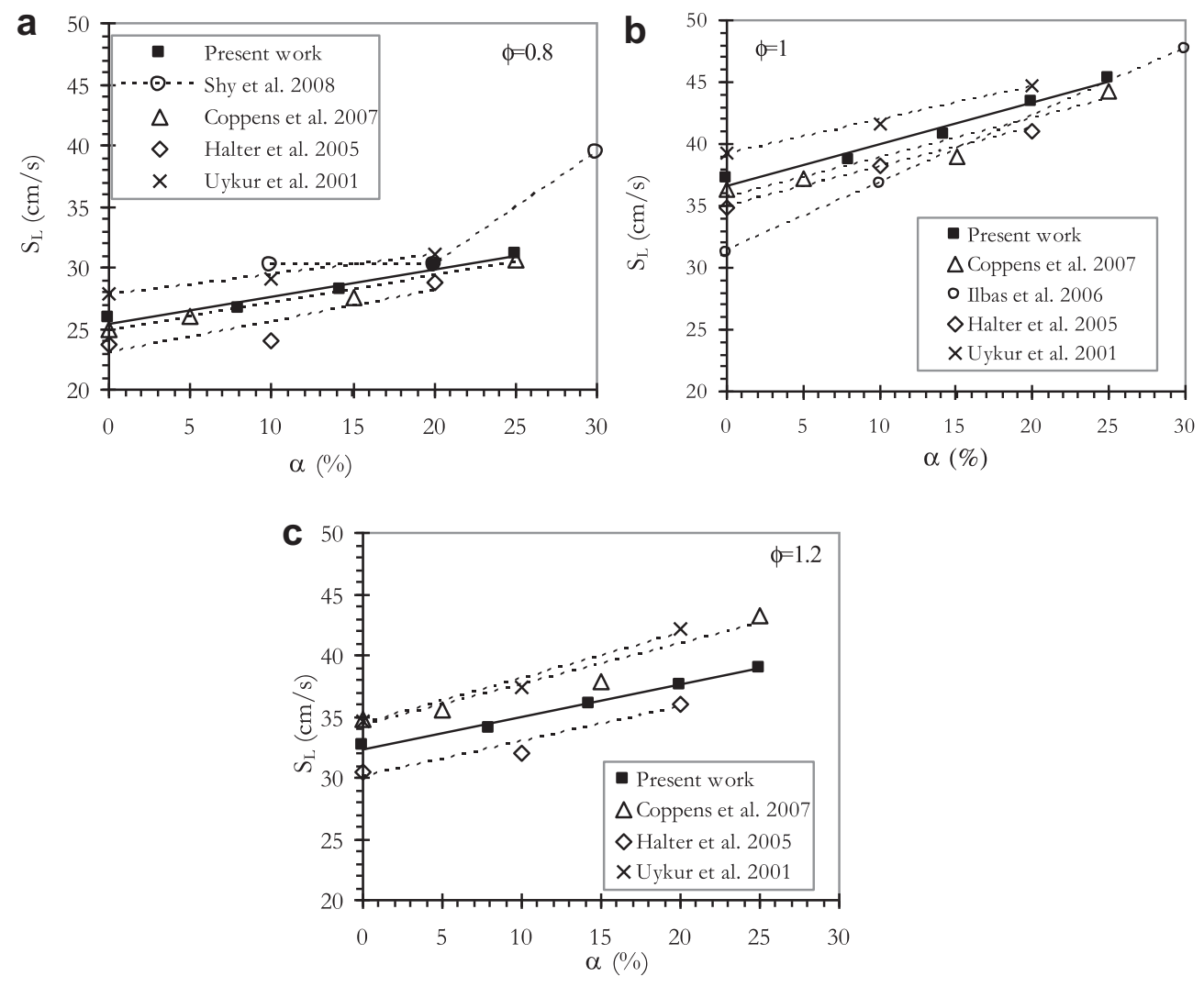

Fig. 5 - Laminar burning velocity versus the percentage of $\mathrm{H}_{2}$ in the fuel at 1 bar pressure and $300 \mathrm{~K}$ for equivalence ratios 0.8 (a), 1 (b) and 1.2 (c). Comparison with experimental results from the literature. 

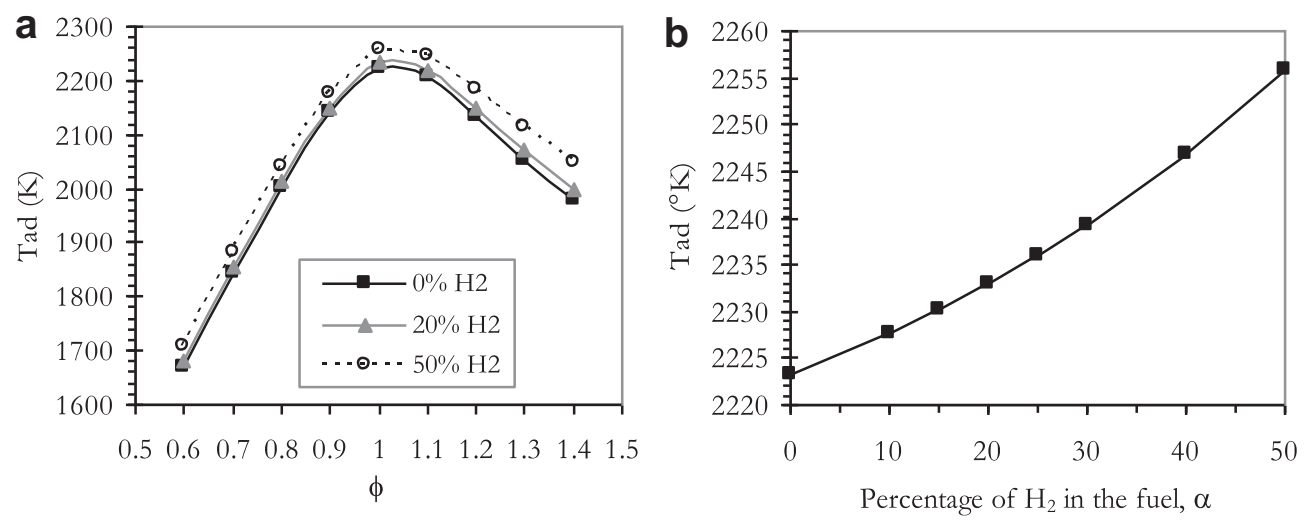

Fig. 6 - a) Calculated adiabatic flame temperature versus equivalence ratio at 1 bar and $300 \mathrm{~K}$ for the percentage of $\mathrm{H}_{2}$ in the fuel 0,20 and $50 \%$; b) adiabatic flame temperature versus the percentage of $\mathrm{H}_{2}$ at $\phi=1$.

temperature becomes significant only over $80 \%$ of $\mathrm{H}_{2}$ based on studies of Tang et al. [53] in a propane-air flame.

\subsection{Effect of steam addition}

This section discusses the effect of steam addition on the laminar burning velocity and the adiabatic flame temperature experimentally and numerically. The chemical kinetic mechanism (GRI-Mech 3.0) used for the calculations has been validated for many cases, but none of these cases addresses the effect of steam addition in the fresh gases. To validate this mechanism it is necessary to make a comparison between the results obtained by this latter and the experimental results obtained in the same operating conditions. The comparison parameter of these two methods is the laminar burning velocity, because this parameter reflects the chemical kinetics of combustion. Two cases of fresh gas temperatures are studied, a standard one of $300 \mathrm{~K}$ with 1 bar of pressure, and the second of $330 \mathrm{~K}$ allowing to increase the rate of water vapor (increase of saturation pressure of water in air).

Fig. 7 shows the experimental results (symbols) and calculations (solid lines) of flame velocity agree very well for a stoichiometric mixture at 1 bar and initial temperatures
$\mathrm{T}_{\mathrm{in}}=300 \mathrm{~K}(\mathrm{a})$ and $330 \mathrm{~K}(\mathrm{~b})$. The GRI-Mech 3.0 mechanism reproduces the laminar burning velocity in the case of steam addition in fresh gases for the two temperatures. The laminar burning velocity decreases gradually as the specific humidity of air increases. This decrease of $S_{L}$ with steam addition is practically linear as found by Mazas et al. [41]. For $T_{\text {in }}=300 \mathrm{~K}$ (Fig. 7a), this decrease is $13.6 \%$ when $S_{H}$ increases from 0 to $21.8 \mathrm{~g} / \mathrm{kg}$ (from 0 to $100 \%$ relative humidity at $300 \mathrm{~K}$ ).

In the case of $T_{\text {in }}=330 \mathrm{~K}$, the flame velocity $S_{L}$ decreases from 42.5 to $20.8 \mathrm{~m} / \mathrm{s}$ for a humidity of $100 \mathrm{~g} / \mathrm{kg}$. The flame velocity is halved in this case; this leads directly to a power reduction, which would require changing the ignition timing. Note that the slope $d S_{L} / d S_{H}$ is approximately the same at $300 \mathrm{~K}$ and $330 \mathrm{~K}$. However, it is possible to achieve higher levels of $S_{H}$ when the air is hot $(330 \mathrm{~K})$, because the saturation $(100 \%$ of relative humidity) is obtained for higher values of $S_{H}$ as shown in Fig. 7b.

The consistency between experiments and modeling of laminar burning velocity was tested in the case of a stoichiometric flame. In order to validate the reaction mechanism, it is necessary to investigate also lean and rich mixtures because the chemical reactions involved during combustion are different. Fig. 8 illustrates the measured (symbols) and
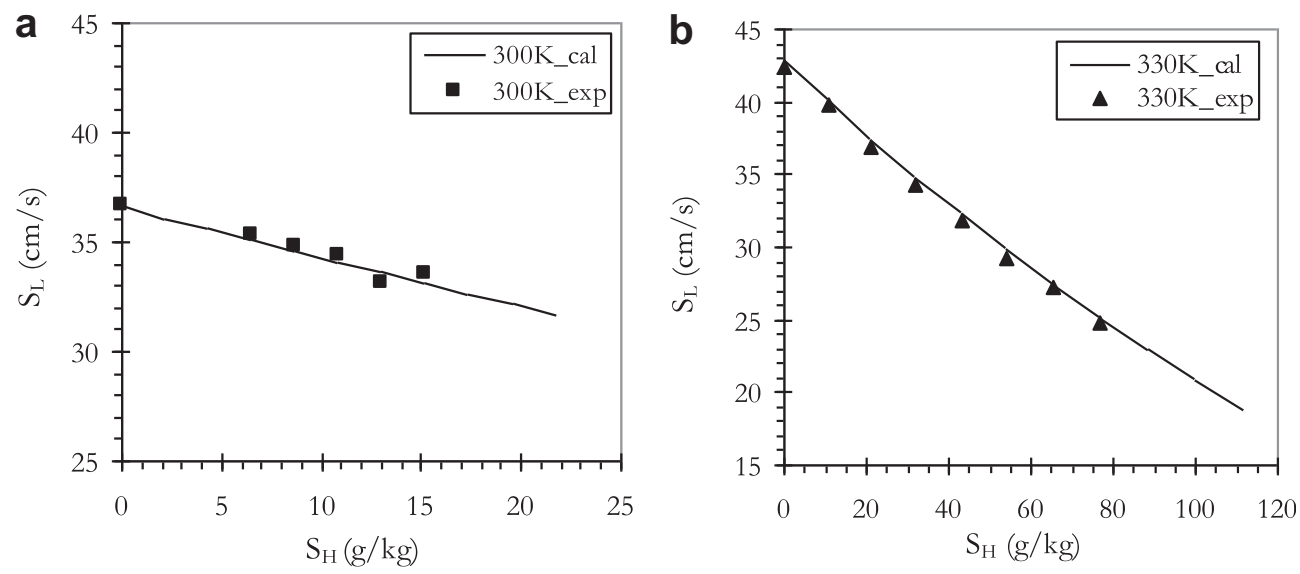

Fig. 7 - Laminar burning velocity versus the specific humidity with $\phi=1$, a) at 1 bar and $300 \mathrm{~K}, \mathrm{~b}$ ) at $1 \mathrm{bar}$ and $330 \mathrm{~K}$. Symbols: experiments, lines: modeling (GRI-Mech 3.0). 


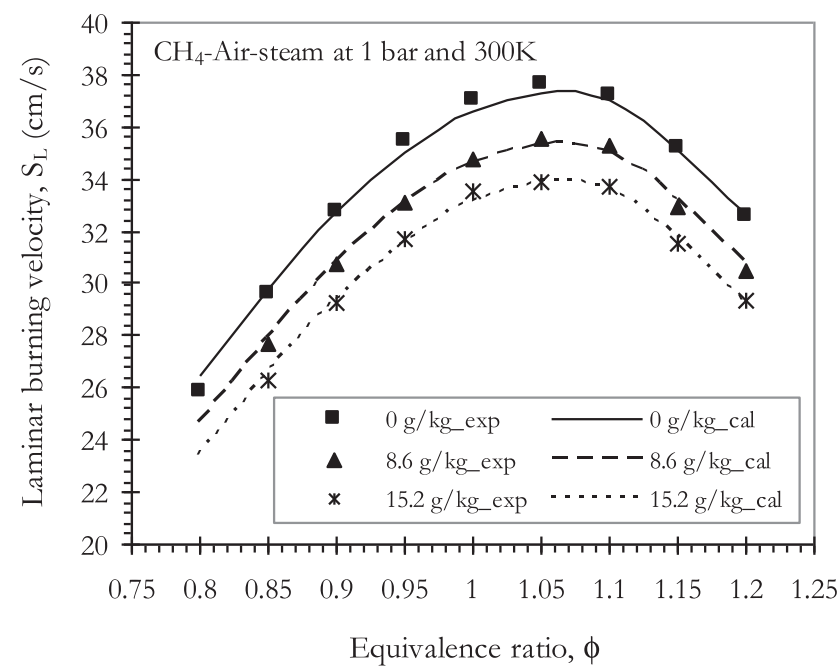

Fig. 8 - Laminar burning velocity versus the equivalence ratio for three different specific humidities $(0,8.6$ and $15.2 \mathrm{~g} / \mathrm{kg}$ ) at $\phi=1,1$ bar and $300 \mathrm{~K}$. Symbols: experiments, lines: modeling (GRI-Mech 3.0).

calculated (lines) laminar burning velocity as a function of equivalence ratio for specific humidity $0,8.6$ and $15.2 \mathrm{~g} / \mathrm{kg}$. The results show the very good agreement between the experimental method and the calculations for the different steam fraction. Note that the humidity effect on the flame velocity is the same whatever the equivalence ratio of mixture.

Other results can be obtained numerically since the chemical kinetic mechanism (GRI-Mech 3.0) is validated for the laminar burning velocity. Fig. 9 depicts the calculated adiabatic flame temperature versus specific humidity for the two initial temperatures $300 \mathrm{~K}$ and $330 \mathrm{~K}$, with $\phi=1$ and $P=1$ bar. These figures show that the flame temperature decreases when the humidity increases. This decrease is about $50 \mathrm{~K}$ from dry air to air fully saturated with water vapor for the

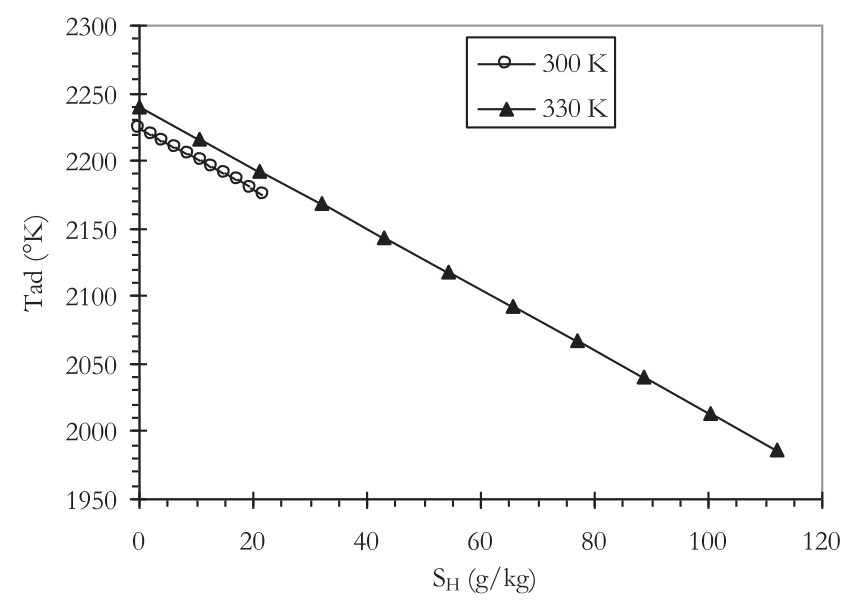

Fig. 9 - Calculated adiabatic flame temperature versus the specific humidity for the two initial temperatures $\mathrm{T}_{\mathrm{in}}=300 \mathrm{~K}\left(\mathrm{~S}_{\mathrm{H} \max }=21.8 \mathrm{~g} / \mathrm{kg}, 100 \%\right.$ of relative humidity $)$ and $T_{\text {in }}=330 \mathrm{~K}\left(\mathrm{~S}_{\mathrm{H} \max }=112.1 \mathrm{~g} / \mathrm{kg}, 100 \%\right.$ of relative humidity), with $\phi=1$ and $P=1$. two cases of initial temperatures. The temperature reduction is due to three phenomena: dilution, calorific capacity and chemistry. The first two effects decrease the flame temperature, while the third tends to increase it [56], however, the overall effect remains a decrease of this temperature. A decrease of flame temperature leads certainly to a decrease of NOx emissions as demonstrated by several studies. It is noted also that the flame temperature decay with the specific humidity is quasi-linear whatever the initial temperature. From these results, it is possible to fit an equation giving the adiabatic flame temperature (Tad) with specific humidity $\left(S_{H}\right)$ :

$\mathrm{T}_{\mathrm{ad}}=\mathrm{T}_{\mathrm{ad}}^{0}-2.25 \times \mathrm{S}_{\mathrm{H}}$

with $\mathrm{T}_{\mathrm{ad}}^{0}$ is the adiabatic flame temperature for a stoichiometric mixture composed of dry air.

\subsection{Effect of isentropic compression}

The good agreement between the experimental method and the calculations allows to validate the reaction mechanism in the case of fresh gas temperatures of 300 and $330 \mathrm{~K}$. In this part of the study, it is assumed that GRI-Mech 3.0 mechanism also remains valid over a larger range of temperature and pressure of fresh gases. This hypothesis is reasonable because many studies have validated the kinetic mechanism for different input parameters $(P, T, \phi)[20,31,32,57]$. In the following, the effects of hydrogen enrichment and steam addition are presented at high pressures and temperatures corresponding to a compression of fresh gases in a piston engine. A spark ignition engine operates on the Beau de Rochas cycle and the thermodynamic state of fresh gases is governed by an isentropic compression. The gas temperature at the end of an isentropic compression can be expressed by the relation:

$\mathrm{T}_{2}=\mathrm{T}_{1}\left(\mathrm{P}_{2} / \mathrm{P}_{1}\right)^{(\gamma-1) / \gamma}$

where $T_{1}$ and $P_{1}$ are the pressure and temperature of the initial state (before compression), $\mathrm{P}_{2}$ is the pressure of compression, and $\gamma=1.4$. In this work, $P_{1}=$ bar, $T_{1}=300 \mathrm{~K}$ and pressure of compression varies from 1 to 50 bar Table 1 gives the temperatures of fresh gases after compression.

Fig. 10 shows the laminar burning velocity as a function of equivalence ratio at 1 and 10 bar in the case of pure $\mathrm{CH}_{4}$ $\left(0 \% \mathrm{H}_{2}\right)$ and in the case of $\mathrm{CH}_{4}-\mathrm{H}_{2}$ mixture $\left(20 \% \mathrm{H}_{2}\right)$. Fig. 11 presents the compression of mixture effect on the laminar burning velocity for a lean flame $(\phi=0.8)$ and stoichiometric flame $(\phi=1)$. The following cases are shown: methane pure $\left(0 \% \mathrm{H}_{2}\right), \mathrm{H}_{2}$ enrichment $\left(20 \% \mathrm{H}_{2}\right)$, and steam addition $(21.8 \mathrm{~g} /$ $\mathrm{kg})$. The compression of fresh gases has a significant effect on the flame velocity with and without hydrogen: when the pressure increases, the flame velocity increases due to the increase of fresh gas temperature induced by the isentropic compression. If the temperature of fresh gases is fixed (e.g. ambient temperature), an increase of pressure leads to a decrease of the flame velocity. This demonstrates that the influence of temperature on the flame velocity is higher than the pressure one. At the stoichiometry, when $P$ increases from 1 to $10 \mathrm{bar}, \mathrm{S}_{\mathrm{L}}$ of pure methane increases from 36.6 to $47.7 \mathrm{~cm} /$ $\mathrm{s}$, an increase of $30.3 \%$. For a mixture with $20 \% \mathrm{H}_{2}, \mathrm{~S}_{\mathrm{L}}$ increases from 42.2 to $55.1 \mathrm{~cm} / \mathrm{s}$ between 0 and 10 bar, this gives almost the same growth rate of $S_{L}(30.6 \%)$. 
Table 1 - Isentropic compression (Eq. (5)) with $P_{1}=1$ bar, $T_{1}=300 \mathrm{~K}$.

\begin{tabular}{|c|c|c|c|c|c|c|c|c|c|c|c|}
\hline$P_{2}$ (bar) & 1 & 2 & 3 & 5 & 7 & 10 & 15 & 20 & 30 & 40 & 50 \\
\hline $\mathrm{T}_{2}(\mathrm{~K})$ & 300 & 365.7 & 410.6 & 475.1 & 523.1 & 579.2 & 650.4 & 706.1 & 792.8 & 860.7 & 917.4 \\
\hline
\end{tabular}

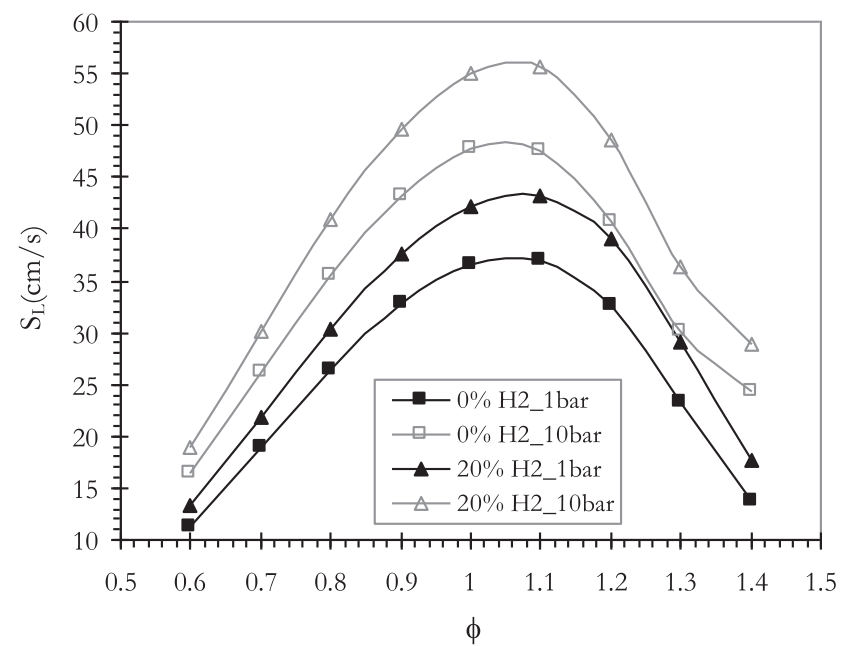

Fig. 10 - Laminar burning velocity versus the equivalence ratio. Effects of hydrogen addition (0 and 20\%) and isentropic pressure ( 1 and $10 \mathrm{bar}$ ).

In the case of steam addition effect (dry air $S_{H}=0 \mathrm{~g} / \mathrm{kg}$ $\left(R_{H}=0 \%\right)$ and a saturated air $\left.S_{H}=21.8 \mathrm{~g} / \mathrm{kg}\left(R_{H}=100 \%\right)\right)$, the results show for $P_{1}=1$ bar, the variation of $S_{L}$ between the case of dry air and saturated air by water vapor is $4.82 \mathrm{~m} / \mathrm{s}$, while this variation is $8.04 \mathrm{~m} / \mathrm{s}$ at $P 1=50$ bar. The effects of $S_{H}$ on $S_{L}$ therefore remain high even when the pressure increases.

\subsection{Correlation of computed $\mathrm{S}_{\mathrm{L}}$ with $\mathrm{P}, \mathrm{T}, \phi$ and $\alpha$}

The laminar burning velocity $\left(\mathrm{S}_{\mathrm{L}}\right)$ of $\mathrm{CH}_{4}-\mathrm{H}_{2}-$ Air depends as is shown above on various parameters: pressure $(P)$,

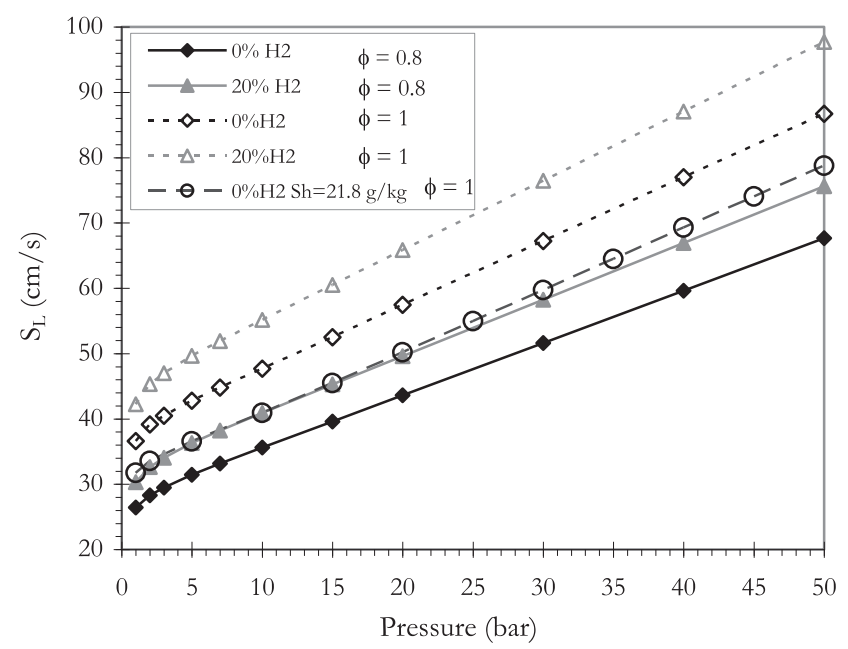

Fig. 11 - Calculated laminar burning velocity versus the isentropic pressure for the cases: $\bullet 0 \% \mathrm{H}_{2}, \mathrm{~S}_{\mathrm{H}}=0, \phi=0.8$; $\Delta 20 \% \mathrm{H}_{2}, \mathrm{~S}_{\mathrm{H}}=0, \phi=0.8 ; \square 0 \% \mathrm{H}_{2}, \mathrm{~S}_{\mathrm{H}}=0, \phi=1 ; \Delta 20 \% \mathrm{H}_{2}$, $\mathrm{S}_{\mathrm{H}}=0, \phi=1 ; \circ 0 \% \mathrm{H}_{2}, \mathrm{~S}_{\mathrm{H}}=21.8 \mathrm{~g} / \mathrm{kg}\left(R_{\mathrm{H}}=100 \%\right), \phi=1$. temperature $(T)$, equivalence ratio $(\phi)$ and fraction of hydrogen in fuel $(\alpha)$. For a given fuel (methane, propane...), Metghalchi and Keck [58] reported a formula of $S_{L}$ as a function of $P$ and $T$ :

$S_{L}(T, P)=S_{L_{0}}\left(T_{0}, P_{0}\right)\left(\frac{T}{T_{0}}\right)^{\beta_{T}}\left(\frac{P}{P_{0}}\right)^{\beta_{P}}$

with $S_{L_{0}}$ the laminar burning velocity under standard conditions of temperature and pressure, and $\beta_{\mathrm{T}}$ and $\beta_{\mathrm{P}}$ are based on equivalence ratio.

With COSILAB code using GRI-Mech 3.0 reaction mechanism, calculations of $S_{L}$ were performed for the following operating conditions: pressure (1-50 bar), temperature (300-917 K), hydrogen fraction (0-0.5) and equivalence ration (0.6-1.4). Basing on these numerical data, fitting equation of the laminar burning velocity of $\mathrm{CH}_{4}-\mathrm{H}_{2}$-air mixture with the different parameters is given below:

$\mathrm{S}_{\mathrm{L}}(\mathrm{T}, \mathrm{P}, \alpha, \mathrm{P})=\mathrm{S}_{\mathrm{L}_{0}}\left(\mathrm{~T}_{0}, \mathrm{P}_{0}, \alpha_{0}, \phi\right)\left(\frac{\mathrm{T}}{\mathrm{T}_{0}}\right)^{\beta_{\mathrm{T}}}\left(\frac{\mathrm{P}}{\mathrm{P}_{0}}\right)^{\beta_{\mathrm{P}}}\left[1+0.02\left(\mathrm{P} / \mathrm{P}_{0}-1\right)\right] \mathrm{F}(\alpha)$

where $T_{0}=300 \mathrm{~K}, P_{0}=1$ bar, $\alpha_{0}=0, B_{P}=-0.54$ and

$S_{L_{0}}=290.15 \phi^{4}-1258.93 \phi^{3}+1837.01 \phi^{2}-1039.57 \phi+208.18$

$\beta_{\mathrm{T}}=-2.08 \phi^{3}+6.92 \phi^{2}-7.61 \phi+4.83$

$F(\alpha)=1.38 \alpha^{2}+0.46 \alpha+1$

The $S_{L}$ formula (eq. (7)) gives values generally consistent with calculations. There is an error of $2.6 \%$ on average over all the results of the studied parameters. However in some cases, the error may reach 7\%, in particular for very high values of $\mathrm{S}_{\mathrm{L}}$.

\section{Conclusion}

In the present paper effects of hydrogen enrichment and steam addition on $\mathrm{CH}_{4}$-air laminar combustion were studied experimentally and computationally, motivated by combustion considerations in engine applications. In the experiment, the laminar burning velocity was measured in a slot burner at atmospheric pressure and temperatures $300 \mathrm{~K}$ and $330 \mathrm{~K}$. The influence of equivalence ratio of mixture is also analyzed. Simulations were performed using COSILAB code with GRIMech 3.0 reaction mechanism, at normal temperature and pressure $(300 \mathrm{~K}, 1 \mathrm{bar})$ to validate the computations. They were then extended to elevated initial pressures and temperatures (up to $917 \mathrm{~K}$ and 50 bar). The main results are summarized as follows:

1. The flame velocity measurements carried out for $\mathrm{CH}_{4}$-air, $\mathrm{CH}_{4}-\mathrm{H}_{2}$-air and $\mathrm{CH}_{4}-\mathrm{Air}-\mathrm{H}_{2} \mathrm{O}$ flames agree with the numerical calculations and with the previous results from 
the literature. It was found that the method of the slot burner used in this study gives satisfactory results.

2. The addition of hydrogen to methane leads to an increase of burning laminar velocity $\left(\mathrm{S}_{\mathrm{L}}\right)$. Indeed at stoichiometric regime, when adding 25\% (by volume) of hydrogen to $\mathrm{CH}_{4}$, the laminar flame velocity increases by $25 \%$ (from 37 to $46 \mathrm{~cm} / \mathrm{s}$ ). The laminar burning velocity increases linearly with increasing hydrogen content, over the range of investigation $\left(0-50 \%\right.$ of $\mathrm{H}_{2}$ ).

3. The presence of vapor water in the fresh gases causes a decrease in flame velocity. This reduction can exceed $50 \%$ between 0 and $100 \%$ humidity in air in the case of fresh gases temperature of $330 \mathrm{~K}$.

4. Adiabatic flame temperature slightly increases with hydrogen enrichment and decreases with steam addition.

5. Effects of fresh gas compression on laminar burning velocity are significant for hydrogen or steam addition. When the pressure increases, the flame velocity increases due to simultaneously increase of fresh gas temperature induced by the isentropic compression. Laminar burning velocity of $\mathrm{CH}_{4}-20 \% \mathrm{H}_{2}$ at the stoichiometry increases by $30.6 \%$ (from 42.2 to $55.1 \mathrm{~cm} / \mathrm{s}$ ) when the fresh gases are compressed between 1 and 10 bar.

6. Based on calculations data, a fitted equation of the laminar burning velocity of $\mathrm{CH}_{4}-\mathrm{H}_{2}$-air mixture is proposed taking into account: pressure, temperature, equivalence ratio and hydrogen fraction in fuel.

\section{Acknowledgments}

This work has been supported by Renault and Humirel/ Measurement Specialties.

\section{R E F E R E N C E S}

[1] Wang J, Huang Z, Miao H, Wang X, Jiang D. Characteristics of direct injection combustion fuelled by natural gas-hydrogen mixtures using a constant volume vessel. Int J Hydrogen Energy 2008;33(7):1947-56.

[2] Ilbas M, Crayford AP, Yilmaz I, Bowen PJ, Syred N. Laminarburning velocities of hydrogen-air and hydrogen-methane-air mixtures: an experimental study. Int J Hydrogen Energy 2006;31(12):1768-79.

[3] Wierzba I, Wang Q. The flammability limits of $\mathrm{H}_{2}-\mathrm{CO}-\mathrm{CH}_{4}$ mixtures in air at elevated temperatures. Int J Hydrogen Energy 2006;31(4):485-9.

[4] do Sacramento EM, de Lima LC, Oliveira CJ, Veziroglu TN. A hydrogen energy system and prospects for reducing emissions of fossil fuels pollutants in the Ceará state-Brazil. Int J Hydrogen Energy 2008;33(9):2132-7.

[5] Granovskii M, Dincer I, Rosen MA. Greenhouse gas emissions reduction by use of wind and solar energies for hydrogen and electricity production: economic factors. Int J Hydrogen Energy 2007;32(8):927-31.

[6] Van Blarigan P, Keller JO. A hydrogen fuelled internal combustion engine designed for single speed/power operation. Int J Hydrogen Energy 1998;23(7):603-9.

[7] Wang J, Huang Z, Fang Y, Liu B, Zeng K, Miao H, et al. Combustion behaviors of a direct-injection engine operating on various fractions of natural gas-hydrogen blends. Int J Hydrogen Energy 2007;32(15 SPEC. ISS.):3555-64.

[8] Saravanan N, Nagarajan G. An experimental investigation of hydrogen-enriched air induction in a diesel engine system. Int J Hydrogen Energy 2008;33(6):1769-75.

[9] Coppens FHV, De Ruyck J, Konnov AA. Effects of hydrogen enrichment on adiabatic burning velocity and NO formation in methane + air flames. Exp Thermal Fluid Sci 2007;31(5): 437-44.

[10] Dryer FL. Water addition to practical combustion systems-concepts and applications. Proc Combust Inst 1977;16(1):279-95.

[11] Blevins L, Roby R. An experimental study of NOx reduction in laminar diffusion flames by addition of high levels of steam. ASME Paper 95-GT-327, 1995.

[12] Correa SM. Power generation and aeropropulsion gas turbines: from combustion science to combustion technology. Proc Combust Inst 1998;27(2):1793-807.

[13] Lif A, Holmberg K. Water-in-diesel emulsions and related systems. Adv Colloid Interface Sci 2006;123-126:231-9 [special issue].

[14] Özcan H, Söylemez MS. Experimental investigation of the effects of water addition on the exhaust emissions of a naturally aspirated, liquefied-petroleum-gas-fueled engine. Energy Fuels 2005;19(4):1468-72.

[15] Subramanian V, Mallikarjuna JM, Ramesh A. Effect of water injection and spark timing on the nitric oxide emission and combustion parameters of a hydrogen fuelled spark ignition engine. Int J Hydrogen Energy 2007;32(9):1159-73.

[16] Van Maaren A, Thung DS, De Goey LPH. Measurement of flame temperature and adiabatic burning velocity of methane/air mixtures. Combust Sci Technol 1994;96(4-6): 327-44.

[17] Vagelopoulos CM, Egolfopoulos FN. Direct experimental determination of laminar flame speeds. Proc Combust Inst 1998;27(1):513-9.

[18] Gu XJ, Haq MZ, Lawes M, Woolley R. Laminar burning velocity and Markstein lengths of methane-air mixtures. Combust Flame 2000;121(1-2):41-58.

[19] Bosschaart KJ, De Goey LPH. The laminar burning velocity of flames propagating in mixtures of hydrocarbons and air measured with the heat flux method. Combust Flame 2004; 136(3):261-9.

[20] Rozenchan G, Zhu DL, Law CK, Tse SD. Outward propagation, burning velocities, and chemical effects of methane flames up to 60 ATM. Proc Combust Inst 2002; 29(2):1461-70.

[21] Edmondson H, Heap MP. The burning velocity of hydrogen-air flames. Combust Flame 1971;16(2):161-5.

[22] Liu DDS, MacFarlane R. Laminar burning velocities of hydrogen-air and hydrogen-airsteam flames. Combust Flame 1983;49(1-3):59-71.

[23] Law CK, Kwon OC. Effects of hydrocarbon substitution on atmospheric hydrogen-air flame propagation. Int J Hydrogen Energy 2004;29(8):867-79.

[24] Dahoe AE. Laminar burning velocities of hydrogen-air mixtures from closed vessel gas explosions. J Loss Prevent Proc Ind 2005;18(3):152-66.

[25] Koroll GW, Kumar RK, Bowles EM. Burning velocities of hydrogen-air mixtures. Combust Flame 1993;94(3):330-40.

[26] Yu G, Law CK, Wu CK. Laminar flame speeds of hydrocarbon + air mixtures with hydrogen addition. Combust Flame 1986;63(3):339-47.

[27] Uykur C, Henshaw PP, Ting DSK, Barron RM. Effects of addition of electrolysis products on methane/air premixed laminar combustion. Int J Hydrogen Energy 2001;26(3): 265-73.

[28] Fells I, Rutherford AG. Burning velocity of methane-air flames. Combust Flame 1969;13(2):130-8. 
[29] Le Cong T, Dagaut P. Experimental and detailed modeling study of the effect of water vapor on the kinetics of combustion of hydrogen and natural gas, impact on NOx. Energy Fuels 2009;23(2):725-34.

[30] Milton BE, Keck JC. Laminar burning velocities in stoichiometric hydrogen and hydrogen-hydrocarbon gas mixtures. Combust Flame 1984;58(1):13-22.

[31] Halter F, Chauveau C, Djebaïli-Chaumeix N, Gökalp I. Characterization of the effects of pressure and hydrogen concentration on laminar burning velocities of methane-hydrogen-air mixtures. Proc Combust Inst 2005; 30(1):201-8.

[32] Hu E, Huang Z, He J, Zheng J, Miao H. Measurements of laminar burning velocities and onset of cellular instabilities of methane-hydrogen-air flames at elevated pressures and temperatures. Int J Hydrogen Energy 2009;34(13):5574-84.

[33] Wang J, Huang Z, Tang C, Miao H, Wang X. Numerical study of the effect of hydrogen addition on methane-air mixtures combustion. Int J Hydrogen Energy 2009;34(2):1084-96.

[34] Tahtouh T, Halter F, Samson E, Mounaïm-Rousselle C. Effects of hydrogen addition and nitrogen dilution on the laminar flame characteristics of premixed methane-air flames. Int J Hydrogen Energy 2009;34(19):8329-38.

[35] Koroll GW, Mulpuru SR. The effect of dilution with steam on the burning velocity and structure of premixed hydrogen flames. Proc Combust Inst 1988;21(1):1811-9.

[36] Kuznetsov M, Redlinger R, Breitung W, Grune J, Friedrich A, Ichikawa N. Laminar burning velocities of hydrogen-oxygen-steam mixtures at elevated temperatures and pressures. Proc Combust Inst 2011;33(1):895-903.

[37] Popov OE, Kusharin AY, Agafonov GL, Gel'fand BE. Inhibition of the combustion of hydrogen-air mixtures containing steam and water aerosol. High Temp 2002;40(5):734-8.

[38] Das AK, Kumar K, Sung CJ. Laminar flame speeds of moist syngas mixtures. Combust Flame 2011;158(2):345-53.

[39] Pareja J, Burbano HJ, Ogami Y. Measurements of the laminar burning velocity of hydrogen-air premixed flames. Int $\mathrm{J}$ Hydrogen Energy 2010;35(4):1812-8.

[40] Babkin V, V'Yun A. Effect of water vapor on the normal burning velocity of a methane-air mixture at high pressures. Combust Explo Shock Waves 1971;7(3):339-41.

[41] Mazas AN, Fiorina B, Lacoste DA, Schuller T. Effects of water vapor addition on the laminar burning velocity of oxygenenriched methane flames. Combust Flame 2011;158(12): 2428-40.

[42] Laffitte P. La Propagation des Flammes Dans Les Mélanges Gazeux, Actualités scientifiques et industrielles. PARIS: Hermann et Cie; 1939.

[43] Law CK. Combustion physics. Cambridge: Cambridge University Press; 2006.
[44] Glassman I, Yetter RA. Combustion. 4th ed. Burlington: Academic Press; 2008.

[45] Poinsot T, Veynante D. Theoretical and numerical combustion. In: Edwards RT, editor. 2nd ed.; 2009.

[46] COSILAB. The combustion simulation laboratory, version 2.1. Bad Zwischenahn (Germany): Rotexo GmbH \& Co.; 2007.

[47] Smith GP, Golden DM, Frenklach M, Moriarty NW, Eiteneer B, Goldenberg M, et al. GRI Mech 3.0, http://www.me.berkeley. edu/gri_mech/; 2006.

[48] Selle L, Poinsot T, Ferret B. Experimental and numerical study of the accuracy of flame-speed measurements for methane/air combustion in a slot burner. Combust Flame 2011;158(1):146-54.

[49] Tatsumi T, Yoshimura T. Stability of the laminar flow in a rectangular duct. J Fluid Mech 1990;212:437-49.

[50] Di Sarli V, Di Benedetto A. Laminar burning velocity of hydrogen-methane/air premixed flames. Int J Hydrogen Energy 2007;32(5):637-46.

[51] Lamoureux N, Djebaïli-Chaumeix N, Paillard CE. Laminar flame velocity determination for $\mathrm{H}_{2}-$ air $-\mathrm{He}-\mathrm{CO}_{2}$ mixtures using the spherical bomb method. Exp Thermal Fluid Sci 2003;27(4):385-93.

[52] Clarke A, Stone R, Beckwith P. Measuring the laminar burning velocity of methane/diluent/air mixtures within a constant-volume combustion bomb in a micro-gravity environment. Inst Energy 1995;68(476):130-6.

[53] Tang C, Huang Z, Jin C, He J, Wang J, Wang X, et al. Laminar burning velocities and combustion characteristics of propane-hydrogen-air premixed flames. Int J Hydrogen Energy 2008;33(18):4906-14.

[54] Huang Z, Zhang Y, Zeng K, Liu B, Wang Q, Jiang D. Measurements of laminar burning velocities for natural gas-hydrogen-air mixtures. Combust Flame 2006;146(1-2): 302-11.

[55] Shy SS, Chen YC, Yang CH, Liu CC, Huang CM. Effects of $\mathrm{H}_{2}$ or $\mathrm{CO}_{2}$ addition, equivalence ratio, and turbulent straining on turbulent burning velocities for lean premixed methane combustion. Combust Flame 2008;153(4):510-24.

[56] Hwang DJ, Park J, Keel SI, Kim TK, Noh DS. Numerical study on flame structure and $\mathrm{NO}$ formation in $\mathrm{CH}_{4}-\mathrm{O}_{2}-\mathrm{N}_{2}$ counterflow diffusion flame diluted with $\mathrm{H}_{2} \mathrm{O}$. Int J Energy Res 2003;28:1255-67.

[57] Bougrine S, Richard S, Nicolle A, Veynante D. Numerical study of laminar flame properties of diluted methane-hydrogen-air flames at high pressure and temperature using detailed chemistry. Int J Hydrogen Energy 2011;36(18):12035-47.

[58] Metghalchi M, Keck JC. Laminar burning velocity of propane-air mixtures at high temperature and pressure. Combust Flame 1980;38:143-54. 